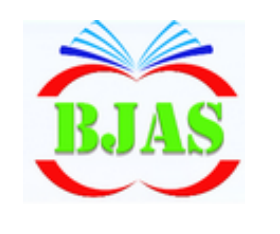

ISSN $1814-5868$
Available online at http://bajas.edu.iq

https://doi.org/10.37077/25200860.2021.34.sp1.4

College of Agriculture, University of Basrah

\section{Rainfall-Runoff Models with Fractional Derivatives Applied to Kurau River Basin, Perak, Malaysia Koichi Unami ${ }^{1, *}$, Rasha M Fadhil ${ }^{2}$ \& Md Rowshon Kamal ${ }^{3}$}

${ }^{1}$ Division of Environmental Science and Technology, Graduate School of Agriculture, Kyoto University, Kyoto, Japan

${ }^{2}$ Department of Dams and Water Resources Engineering, College of Engineering, University of Mosul, Iraq

${ }^{3}$ Department of Biological Agricultural Engineering, Faculty of Engineering, Universiti Putra Malaysia, Malaysia

Received 10 April 2020; Accepted 2 March 2021; Available online 19 August 2021

\begin{abstract}
Kurau River Basin (KRB), which covers an area of $322 \mathrm{~km}^{2}$ and is the main drainage artery pouring into Bukit Merah Reservoir (BMR), is located in Perak State of Malaysia. The study of rainfall-runoff processes in KRB is important because BMR plays a vital role in rice production, flood control, ecosystems, and tourism in the region. This study proposes a new approach to rainfall-runoff modeling based on the fractional calculus. A dataset of daily rainfall and streamflow has been acquired. Then, the standard linear autoregressive with exogenous input (ARX) model is identified from the dataset in the sense of least square error. We consider the ARX model as a discretized differential equation with fractional orders. Such a model with fractional derivatives is versatile to represent hysteresis, which is intrinsically linked to the real runoff processes in tropical catchment basins like KRB.
\end{abstract}

Keywords: Runoff analysis, ARX model, Fractional calculus, Malaysia.

\section{Introduction}

Runoff analysis in general is to establish an input-output relationship between weather data and streamflow, including the errors between observed and estimated streamflow time series in the model structure. According to Yeh (1985), a simple stochastic model may yield better prediction of hydrological time series than a more complex deterministic model. Furthermore, hydrological time series are non-deterministic in nature and therefore cannot be predicted with certainty for future. Stochastic models are preferred also in this context as the probabilistic limits for prediction may readily be obtained. Though a stochastic model can be either linear or nonlinear, considering probability distributions of errors makes it possible that a linear stochastic model describes the complexity of time series in the real world despite its relative simplicity (Lohani et al., 2012). As a result, linear stochastic models have been intensively researched in the context of system theory (Unami \& Kawachi, 2005). Among such linear stochastic models, 
linear autoregressive with exogenous input (ARX) models are commonly employed in hydrological engineering, in order to consider the effect of rainfall as exogenous input on streamflow having autoregressive properties. Osman et al. (2019) gave an example of such application of ARX models to analysis of rainfall-runoff processes.

The objective of this study is to initiate a new approach to rainfall-runoff analysis with ARX models based on the fractional calculus. The notion of fractional calculus attracts attention of scientists in these decades because of its potential to model different practical phenomena including population dynamics (Bushnaq et al., 2018a), HIV/AIDS infection (Bushnaq et al., 2018b), and infiltration of water into soil (Fernández-Pato et al., 2018). A rainfall-runoff model with a fractional differential equation has been developed in the pioneering work of Guinot $e t$ al. (2015). In this study, a dataset of daily rainfall and streamflow has been firstly obtained from a study area referred to as Kurau River Basin (KRB). Then, the standard linear ARX model is identified from the dataset in the sense of least square error. We regard the ARX model as a discretized differential equation with fractional orders to establish its continuous time counterpart. Unlike the unit hydrograph theory which has been already applied to KRB (Hassan \& Harun, 2011), such a differential equation with fractional derivatives is versatile to represent hysteresis, which is intrinsic to the real rainfall-runoff processes in large tropical catchment basins like KRB. Finally, the response of the streamflow to the rainfall is evaluated in the frequency domain (Jarad \& Abdeljawad, 2018).

\section{Materials \& Methods}

\section{Description of study area}

$\mathrm{KRB}$ is located between $04^{\circ} 51^{\prime} \mathrm{N}$ and $05^{\circ}$ $10^{\prime} \mathrm{N}$ latitude and $100^{\circ} 38^{\prime} \mathrm{E}$ to $101^{\circ} 01^{\prime} \mathrm{E}$ longitude in Perak State of Malaysia, having an area of $322 \mathrm{~km}^{2}$ and being the main drainage artery pouring into Bukit Merah Reservoir (BMR) (Fadhil et al., 2017). Analysis of rainfall-runoff processes in KRB is important because BMR is the key structure for rice production, flood control, ecosystems, and tourism in the region (Hamidon et al., 2015). BMR, constructed in the year 1906 in the Northwest of Perak State, Malaysia, is an important water source for the Kerian Irrigation Scheme (KIS), which is one of the country's eight largest granaries with net paddy area of $235.6 \mathrm{~km}^{2}$ (Malaysia DID, 2011). The total catchment area of BMR is $682 \mathrm{~km}^{2}$. The KIS receives about $61 \%$ of the irrigation water demand from BMR and the rest from rainfall. Furthermore, BMR provides fresh water to achieve the domestic and industrial demands to Kerian District as well as Larut Matang District. The Kurau River is the largest of the streams filling BMR.

KRB has two tributaries of Ara and Kurau rivers with confluence at Pondok Tanjung town (Ismail \& Najib, 2011). The land use delineated by Hassan et al. (2012) consists of forestry $46 \%$ and agriculture $43 \%$. The half of the land is owned by individual farmers, which makes it difficult to enforce sound land use management policies for this watershed. Ghani et al. (2011) described hydraulic details of Kurau river. Daily data of rainfall as well as daily streamflow records observed at the station No. 15007421 near that confluence point are obtained from Malaysian authority 
for a four years period 1991-1994 and a 1 year period 1998. Fig. 1 is a photo showing

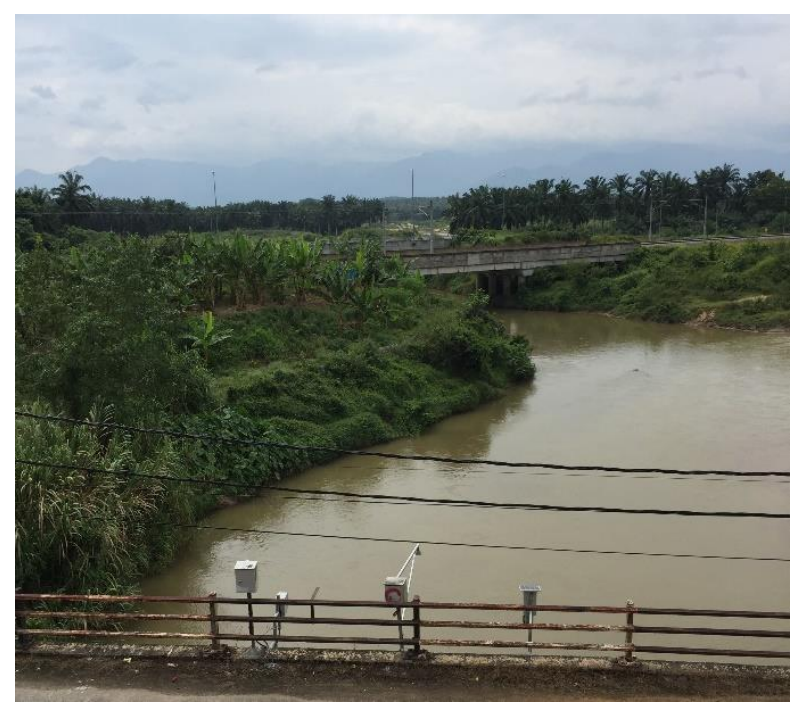

Fig. (1): The landscape of KRB including the streamflow sensor (photo taken on August 4, 2017).

\section{Structure of the ARX model}

The ARX model applied to the KRB assumes a linear Markovian input-output relationship between rainfall and streamflow. Discrete time series with a length $n$ of observed rainfall and specific streamflow discharge are denoted by $R_{i}$ and $Q_{i} \quad(0 \leq i<n)$, respectively. In order to make the ARX model homogeneous, an offset $\Delta$ is introduced to define the output variable $z_{i}$ as

$$
z_{i}=Q_{i}+\Delta
$$

Then, the ARX model is written as

$$
z_{p+i}=\sum_{k=0}^{k<p}\left(K_{p-1-k} z_{k+i}+K_{2 p-1-k} R_{k+i}\right)+e_{p+i}
$$

where $p$ is the order representing the number of lagged time steps $(0<p<n), K_{k}$ $(0 \leq k<2 p)$ are model coefficients, and $e_{p+i}$ $(0 \leq i<n-p)$ are errors. Substituting (1) into (2) results in the landscape of KRB including the streamflow sensor.

$$
\begin{aligned}
Q_{p+i} & =\sum_{k=0}^{k<p}\left(K_{p-1-k} Q_{k+i}+K_{2 p-1-k} R_{k+i}\right) \\
& +\left(\sum_{k=0}^{k<p} K_{p-1-k}-1\right) \Delta+e_{p+i}
\end{aligned}
$$

for $0 \leq i<n-p$, which comprise a linear equations system

$$
\mathbf{Q}=X \mathbf{K}+\mathbf{e}
$$

where

$$
\mathbf{Q}=\left(\begin{array}{c}
Q_{p} \\
\vdots \\
Q_{p+i} \\
\vdots \\
Q_{n-1}
\end{array}\right), \quad \mathbf{K}=\left(\begin{array}{c}
K_{0} \\
\vdots \\
K_{p-1} \\
\vdots \\
K_{2 p-1} \\
c
\end{array}\right), \quad \mathbf{e}=\left(\begin{array}{c}
e_{p} \\
\vdots \\
e_{p+i} \\
\vdots \\
e_{n-1}
\end{array}\right)
$$

with $c=\left(\sum_{k=0}^{k<p} K_{p-1-k}-1\right) \Delta$, and

$$
X=\left(\begin{array}{ccccccc}
Q_{p-1} & \cdots & Q_{0} & R_{p-1} & \cdots & R_{0} & 1 \\
\vdots & \vdots & \vdots & \vdots & \vdots & \vdots & \vdots \\
Q_{p-1+i} & \cdots & Q_{i} & R_{p-1+i} & \cdots & R_{i} & 1 \\
\vdots & \vdots & \vdots & \vdots & \vdots & \vdots & \vdots \\
Q_{n-2} & \cdots & Q_{n-p-1} & R_{n-2} & \cdots & R_{n-p-1} & 1
\end{array}\right)
$$

Assuming that the vector $\mathbf{K}$ of model coefficients is time invariant with the statistically equilibrium error vector $\mathbf{e}$, the square norm $\sqrt{\mathbf{e}^{T} \mathbf{e}}$ of $\mathbf{e}$ is minimized by the least square method computing $\mathbf{K}$ as

$$
\mathbf{K}=\left(X^{T} X\right)^{-1} X^{T} \mathbf{Q},
$$

which is a regular linear system.

\section{Fractional differential equation approximating the ARX model}

According to Oldham \& Spanier (1974), the $\alpha$-th fractional derivatives of $z$ as a smooth 
function of the time $t$ (day) are approximated as

$$
\frac{d^{\alpha} z}{d t^{\alpha}} \approx \frac{\sum_{k=0}^{k<p} \Delta z_{k} \Delta f_{k}+\frac{1-\alpha}{p^{\alpha}} z_{i}}{\Gamma(2-\alpha)}=\sum_{k=0}^{k \leq p} c_{\alpha, k} z_{i+p-k}
$$

for $0 \leq \alpha<1$ with $\Delta z_{k}=z_{i+p-k}-z_{i+p-1-k}$ and $\Delta f_{k}=(k+1)^{1-\alpha}-k^{1-\alpha}$, and

$$
\frac{d z}{d t} \approx \frac{z_{i+p}-z_{i}}{p}=\sum_{k=0}^{k \leq p} c_{1, k} z_{i+p-k}
$$

which are linear combinations of $z_{i+p-k}$. Here, the fractional orders are chosen as $\alpha=k / p$ for $k=0, \cdots, p$, so that an approximation

$$
\sum_{k=0}^{k \leq p} a_{k} \frac{d^{k / p} z}{d t^{k / p}} \approx z_{p+i}-\sum_{k=0}^{k<p} K_{p-1-k} z_{k+i}
$$

holds with

$$
M\left(\begin{array}{c}
a_{0} \\
a_{1} \\
\vdots \\
a_{p}
\end{array}\right)=\left(\begin{array}{c}
1 \\
-K_{0} \\
\vdots \\
-K_{p-1}
\end{array}\right)
$$

where $M$ is the $(p+1) \times(p+1)$ matrix whose $(i, j)$ th entry is $c_{j / p, p-i}$. Then, a nominal rainfall-runoff model with fractional derivatives is represented as a transfer function

$$
P(s)=\frac{1-\exp (-s)}{s} \frac{\sum_{k=0}^{k<p} K_{p+k} \exp (-k s)}{\sum_{k=0}^{k \leq p} a_{k} s^{k / p}}
$$

Where $s$ is the complex frequency in the Laplace transform.

\section{Results \& Discussion}

\section{Identification of the ARX model}

The coefficients $K_{k}$ of the ARX model is calculated from the observed data series during the 4 years period of 1991-1994 using (7) for different values of the order $p$. This procedure is considered as training. Although a systematic method such as Akaike information criteria (Akaike, 1974) was not used, it turned out that the order $p$ of ARX can be taken as small as 6 . Indeed, taking the order $p$ as $7,14,28,120$, and 360 results in similar consequence that the streamflow depends mostly on the streamflow the day before and the rainfall in the preceding 6 days. The coefficients $K_{k}$ for $p=6$ are shown in Table 1 , and the offset $\Delta$ is equal to 0.0034. Three popular statistical indicators assessing the performance of the ARX model applied to the data series are evaluated as $\mathrm{R}^{2}=0.71$ (the coefficient of efficiency), $\mathrm{NSE}=0.71$ (Nash-Sutcliffe efficiency), and PBIAS $=0.00$ (percent bias), implying good accuracy in the conventional sense.

Table (1): Identification results for coefficients of the ARX model.

\begin{tabular}{cc|cc}
\hline$K_{0}$ & 0.5758 & $K_{6+0}$ & 0.0316 \\
$K_{1}$ & -0.0410 & $K_{6+1}$ & 0.0137 \\
$K_{2}$ & 0.0773 & $K_{6+2}$ & 0.0465 \\
$K_{3}$ & 0.0971 & $K_{6+3}$ & 0.1982 \\
$K_{4}$ & 0.0504 & $K_{6+4}$ & 0.2384 \\
$K_{5}$ & 0.0274 & $K_{6+5}$ & 0.0427 \\
\hline
\end{tabular}

The PBIAS is equal to zero because of a property of the least square method employed. 


\section{Validation of the ARX model}

The identified ARX model is validated with the other observed data series during the 1 year period of 1998. The statistical indicators evaluated as $\mathrm{R}^{2}=0.75, \mathrm{NSE}=0.74$, and $\mathrm{PBIAS}=2.70$ imply slightly better performance in terms of efficiency, and therefore the identified ARX model is considered acceptable for representing the rainfall-runoff process over the discrete time domain.

\section{Nominal rainfall-runoff model with fractional derivatives}

The fractional differential equation representing the rainfall-runoff process over the continuous time domain is finally obtained as

$$
\begin{aligned}
& -22.25 Q_{t}+51.16 \frac{d^{1 / 6} Q_{t}}{d t^{1 / 6}} \\
& -17.60 \frac{d^{1 / 3} Q_{t}}{d t^{1 / 3}}-18.11 \frac{d^{1 / 2} Q_{t}}{d t^{1 / 2}} \\
& -2.663 \frac{d^{2 / 3} Q_{t}}{d t^{2 / 3}}+11.00 \frac{d^{5 / 6} Q_{t}}{d t^{5 / 6}} \\
& -6.667 \frac{d Q_{t}}{d t} \\
& =0.0316 R_{t}+0.0137 R_{t-1}+0.0465 R_{t-2} \\
& +0.1982 R_{t-3}+0.2384 R_{t-4} \\
& +0.0427 R_{t-5}+0.0756
\end{aligned}
$$

and the gain $|P(\sqrt{-1} \omega)|$ of the transfer function (12) for the frequency $\omega$ is plotted in Fig. 2. Its principal poles are $0.08563 \pm 0.1413 \sqrt{-1}$. It is noteworthy that the real part of the principal poles is positive, implying that the response of the streamflow to the rainfall is unstable. Since the ARX model was identified with the least square sense, this fractional differential equation (13) should be considered as nominal. Due to the terms of fractional derivatives, the gain attains a notable peak at the frequency around $\omega=\pi / 16$ (1/day), implying that the dominant lag time of the rainfall-runoff process is about $16 / \pi \approx 5$ days. The vanishing gain at higher frequency domain represents that rainfall fluctuations within short period like 1 day does not appear in the stream flow

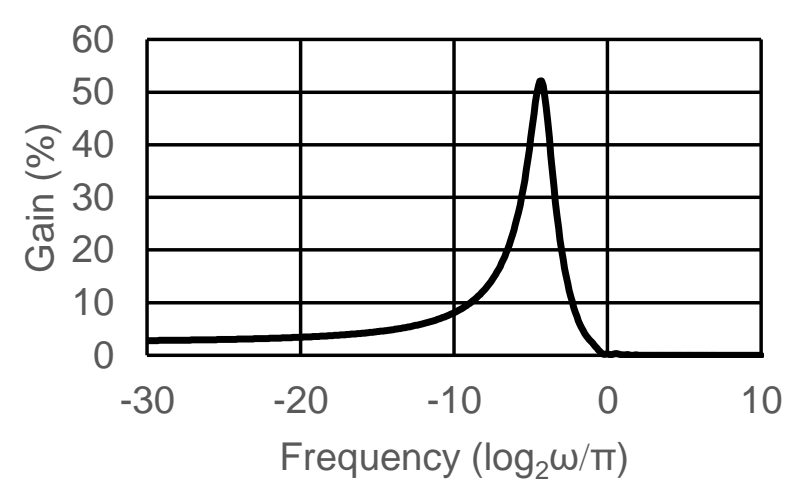

fluctuations.

\section{Fig. (2) Gain of the transfer function representing the nominal rainfall-runoff process.}

\section{Conclusions}

The new approach to rainfall-runoff analysis with ARX models based on the fractional calculus is advantageous because of its capability of representing dynamic causality in hydrological phenomena. The linearity of the models admits application of the linear control theory, and therefore a large variety of problems involving feed-back systems can be tackled with them. Reservoir operation and real-time flood control are major two examples of such feed-back systems in water resources management. While, the unstable fractional differential equation implicates the very complex hydrology in $\mathrm{KRB}$.

This study exclusively dealt with the nominal model, and perturbation structure of 
actual transfer functions from the nominal one shall be researched for further understanding of stochastic dynamics in the rainfall-runoff processes.

\section{Acknowledgements}

The authors thank Malaysian authorities including the Department of Irrigation and Drainage (DID), IADA Kerian Irrigation Scheme, and the Department of Agriculture (DOA) for the provision of the reservoir management report and spatial and hydrometeorological data. The Ministry of Higher Education and Higher Education, Iraq and University of Mosul, Iraq are acknowledged for providing the scholarship to the second author. This research is funded by Putra Grant No. 9406300 from the Universiti Putra Malaysia and Grants-in-Aid for Scientific Research No. 16KT0018 and No.19KK0167 from the Japan Society for the Promotion of Science (JSPS). The computed principal poles of the transfer functions are obtained from Wolfram|Alpha.

\section{Conflicts of interest}

The authors declare that they have no conflict of interests.

\section{References}

Akaike, H. (1974). A new look at statistical-model identification. IEEE T. Automat. Contr., AC19, 716-723.

https://ieeexplore.ieee.org/document/1100705

Bushnaq, S., Ali, S., Shah, K., \& Arif, M. (2018a). Exact solution to non-linear biological population model with fractional order. Therm. Sci., 22, S317S327.https://pdfs.semanticscholar.org/a360/787b5e 0f1abde25a787b8f3c28c2132b0c03.pdf

Bushnaq, S., Khan, S.A., Shah, K., \& Zaman, G. (2018b). Mathematical analysis of HIV/AIDS infection model with Caputo-Fabrizio fractional derivative. Cogent Math., 5, 1432521. https://www.cogentoa.com/article/10.1080/2331183 5.2018.1432521

Fadhil, R. M., Rowshon, M. K., Ahmad, D., Fikri, A., \& Aimrun, W. (2017). A stochastic rainfall generator model for simulation of daily rainfall events in Kurau catchment: model testing. Acta Horticulturae, 1152, 1-10. https://www.ishs.org/ishs-article/1152_1

Fernández-Pato, J., Gracia, J.L. \& Garcia-Navarro, P. (2018). A fractional-order infiltration model to improve the simulation of rainfall/runoff in combination with a $2 \mathrm{D}$ shallow water model. $J$. Hydroinform., $\quad 20, \quad$ 898-916. http://scholar.google.es/citations?user=dD4cnfYAA AAJ\&hl=es

Ghani, A. A., Azamathulla, H. M., Chang, C. K., Zakaria , N. A., \& Abu Hasan, Z. (2011). Prediction of total bed material load for rivers in Malaysia: A case study of Langat, Muda and Kurau Rivers. Environmental Fluid Mechanics, 11, 307318 .

Guinot, V., Savean, M., Jourde, H., \& Neppel, L. (2015). Conceptual rainfall-runoff model with a two-parameter, infinite characteristic time transfer function. Hydrological Processes, 29, 4756-4778. https://doi.org/10.1002/hyp.10523

Hamidon, N., Harun, S., Malek, M. A., Ismail, T., \& Alias, N. (2015). Prediction of paddy irrigation requirements by using statistical downscaling and CROPWAT models: a case study from the Kerian Irrigation Scheme in Malaysia. Journal Teknologi, 76, 281-288. https://doi.org/10.11113/JT.V76.4038

Hassan, Z., \& Harun, S. (2011). Hydrological response of a catchment to climate change in the Kurau River Basin, Perak, Malaysia, 3rd International Conference on Managing Rivers in the 21th Century: Sustainable Solutions for Global Crisis of Flooding, Pollution and Water Scarcity, Penang, Malaysia, 216-225.

Hassan, Z., Harun, S., \& Malek, M.A. (2012). Application of ANNs model with the SDSM for the hydrological trend prediction in the sub-catchment of Kurau River, Malaysia. Journal of Environmental Science and Engineering, B: 1(5B), 577-585.

Ismail, W. R., \& Najib, S. A. M. (2011). Sediment and nutrient balance of Bukit Merah Reservoir, Perak

The $5^{\text {th }}$ International Conference on Agricultural and Food Engineering (CAFEi) 2021 
(Malaysia). Lakes and reservoirs: Research and Management, 16 ,

179-184. https://doi.org/10.1111/j.1440-1770.2011.00453.x

Jarad, F. \& Abdeljawad, T. (2018). A modified Laplace transform for certain generalized fractional operators. Results in Nonlinear Analysis, 1, 88-98. https://dergipark.org.tr/en/download/articlefile/527716

Lohani, A.K., Kumar, R., \& Singh, R. D. (2012). Hydrological time series modeling: A comparison between adaptive neuro-fuzzy, neural network and autoregressive techniques. Journal of Hydrology, 442 , 23-35. https://doi.org/10.1016/j.jhydrol.2012.03.031

Malaysia DID (2011). Review of the national water resources study (2000-2050) and formulation of national water resources policy: Final report. Kementerian Sumber Asli Dan Alam Sekitar Malaysia.

https://www.water.gov.my/jps/resources/PDF/Hydr ology\%20Publication/Vol2WaterGovernance.pdf
Oldham, K. B., \& Spanier, J. (1974). The Fractional Calculus. Academic Press, Inc.: 234pp. https://link.springer.com/chapter/10.1007/978-37091-2664-6_5

Osman, Y., Al-Ansari, N., \& Abdellatif, M. (2019). Climate change model as a decision support tool for water resources management in northern Iraq: a case study of Greater Zab River. Journal of Water and Climate Change, 10, 197-209. https://doi.org/10.2166/wcc.2017.083

Unami, K., \& Kawachi, T. (2005). Systematic assessment of flood mitigation in a tank irrigated paddy fields area. Paddy and Water Environment, 3, 191-199.https://doi.org/10.1007/s10333-0050022-6

Yeh, W. W. G. (1985). Reservoir management and operations models - a state-of-the-art review. Water Resources Research, 21, 1797-1818. https://doi.org/10.1029/WR021i012p01797 